\title{
O PAPEL DA FÉ E CRENÇAS NO SENTIDO DE VIDA
}

\author{
The role of faith and beliefs in the meaning of life
}

\author{
Cléia Zanatta ${ }^{1}$ \\ Michelle Pinheiro Imbelloni ${ }^{2}$ \\ Luís Antônio Monteiro Campos ${ }^{3}$ \\ Luciana Cordeiro Telles ${ }^{4}$
}

\begin{abstract}
RESUMO
O presente trabalho tem como tema o papel da fé e crenças de sentido da vida, com o propósito de relacionar os temas adotando-se uma abordagem filosófica, teológica e psicológica. Optouse por adotar abordagem logoterapêutica no âmbito psicológico sobre o sentido de vida. Como problema a ser investigado foi elaborada a seguinte questão: que relação se pode estabelecer entre fé e sentido da vida? Foram determinados os seguintes objetivos para elaboração destas reflexões: realizar estudos sobre o tema fé à luz da Psicologia, da Teologia e da Filosofia e; analisar o conceito de sentido da vida no âmbito da Filosofia, da Teologia e da Psicologia, adotando-se nesse caso a abordagem da Logoterapia; e relacionar fé e sentido de vida a partir das contribuições da Filosofia, da Teologia e da Psicologia. Trata-se de pesquisa teórica de base bibliográfica motivada por leituras que evidenciaram a relação entre os campos teóricos investigados para subsidiar os conceitos fé e crenças no sentido de vida. O estudo visou conhecer os pontos convergentes e contribuir para a reflexão sobre o tema, direcionado aos estudiosos de Filosofia, Teologia e Psicologia. Pode-se verificar que é a fé em algo que está por vir, que move o agir e ressignifica o momento presente atribuindo, assim, um sentido à vida.
\end{abstract}

Palavras-chave: Fé, Crenças, Sentido da Vida

\begin{abstract}
The present work treats of the role of faith and beliefs in the meaning of life, aiming to relate them to each other with a philosophical, theological, and psychological approach. A logotherapeutic approach in the psychological sphere about the meaning of life was chosen. As a problem to be investigated, the following question was raised: "What relationship can be established between faith and the meaning of life?”. The following goals for these reflections were settled: to carry out studies on the theme of faith in the light of Psychology, Theology and Philosophy and to analyze the concept of the meaning of life in the scope of Philosophy, Theology and Psychology, adopting the approach of Logotherapy; and to relate faith and meaning of life from the contributions of Philosophy, Theology and Psychology. This is a theoretical research with a bibliographic basis motivated by readings that show the relationship between the theoretical fields investigated to support the
\end{abstract}

\footnotetext{
${ }^{1}$ Professora da graduação e do Mestrado em Psicologia na Universidade Católica de Petrópolis (UCP-RJ). Contato: cleia.zanatta@ucp.br

${ }^{2}$ Graduada em Psicologia pela Universidade Católica de Petrópolis (UCP-RJ) especialista em Logoterapia e Análise Existencial. Contato: michelle_imbelloni@hotmail.com

${ }^{3}$ Professor da graduação e Coordenador do Mestrado em Psicologia na Universidade Católica de Petrópolis (UCPRJ), professor na PUC-Rio e na UNILASALLE - RJ. Contato: campox1@gmail.com

${ }^{4}$ Graduada em Fisioterapia (UNESA) e Teologia (Faculdade São Bento- RJ), especialista em Logoterapia e Análise Existencial pela Universidade Católica de Petrópolis (UCP-RJ) e Mestre em Psicologia pela Universidade Católica de Petrópolis (UCP-RJ). Contato: cordeirotelles@gmail.com
} 
concepts of faith and beliefs in the sense of life. The study aimed to acknowledge the converging points and contribute to a reflection on the theme, aiming scholars of Philosophy, Theology and Psychology. It was verified that it is faith in something that is to come, that moves action and resignifies the present moment, thus attributing a meaning to life.

Keywords: Faith, Beliefs, Meaning of Life

\section{Introdução}

O presente artigo tem como tema relacionar o papel da fé e as crenças no sentido de vida. Poderiam ser observados vários caminhos para nortear este estudo, porém, optou-se por correlacionar o fenômeno fé com o tema sentido de vida, adotando-se uma abordagem psicológica particularmente da logoterapia, teológica e filosófica dos termos, uma vez que essas ciências refletem sobre os conceitos em questão e oferecem pontos de convergência que favorecem compreender os temas analisados e fortalecer a idéia de que os mesmos são alvo de interesse de conhecimentos diversos, pois evidenciam necessidades básicas para sustentar a existência humana.

A fé constitui tema principal da Teologia, alvo de reflexão de filósofos e nos estudos de Psicologia, está relacionado ao tema crenças, que é particularmente abordado pela Psicologia Cognitiva e Social.

Crenças constituem, para Le Bon (2001), o conjunto de dogmas externos, não comprováveis ou experimentados pelo indivíduo ou pela coletividade e compõe um sistema de valores com base no consenso da maioria. Para KRÜGER (2018, p. 32), “as crenças influenciam decisivamente comportamentos e condutas pois, determinam as formas como as pessoas estabelecem relações, nas situações sobres as quais interagem, dando-lhes o convencimento para justificarem seus comportamentos”.

Para nortear as reflexões sobre o tema deste artigo, optou-se por definir como foco a ser estudado a seguinte questão: que relações se pode estabelecer entre fé e sentido de vida?

Em uma pesquisa empírica de Aquino et al. (2013) constata-se a relação da fé com o sentido da vida e nesse contexto admite-se, no cotidiano da vida humana, que realizar sentidos para viver constitui uma força vital que dialoga frequentemente com as concepções sobre fé, como se pode verificar no enfrentamento, por exemplo, que o homem é capaz de fazer frente à morte de um ente querido. Numa experiência assim, vêse que a fé costuma assumir o papel primordial na superação da dor. O tema proposto neste artigo tem esta direção como motivo de reflexão - a papel da fé e crenças no sentido 
da vida.

Objetivou-se realizar estudos sobre o tema fé à luz da Psicologia, da Teologia e da Filosofia; analisar o conceito de sentido da vida no âmbito da Filosofia, da Teologia e da Psicologia, adotando-se nesse caso a abordagem da Logoterapia; e relacionar fé e sentido de vida a partir das contribuições da Filosofia, da Teologia e da Psicologia.

O estudo justifica-se pelo interesse em conhecer os pontos de convergência entre essas três áreas do conhecimento acerca dos temas, considerando tratar-se de temas humanos, que interessam a quem com eles atuam ou sobre eles estudam.

Para Dantas e Tobler (2003), a análise do sofrimento e de suas facetas de representação e de expressão não é tarefa fácil. Isto porque, para as autoras, o sofrimento revela-se de modo ambíguo. Aparentemente ele pode estar relacionado à perda - dor moral ou psíquica - ou a manifestações de natureza somática - dor física. O sofrimento pode surgir nas diversas circunstâncias da vida e apresentar-se de diversos modos, porém, deve haver um núcleo comum a todos os modos de sofrer. No início do pensamento filosófico da humanidade, questões relacionadas ao sentido da existência humana permeavam a preocupação dos filósofos. Entretanto, esta não era uma questão religiosa, era mais racional. Contudo, o sentido da vida estava sempre relacionado à busca de felicidade ou da realização plena do ser humano (ZILLES, 1991).

A visão científica do universo, e a constatação das suas dimensões incompreensíveis, geraram espanto e angústia em filósofos como Pascal (1952 apud LE BON, 2001). Qual o sentido da vida, num cosmo como o descrito pela ciência? Logo, o homem começou a enfrentar o sentido da brevidade da vida.

Quando considero a curta duração da minha vida, e o estar a ser engolido pela eternidade do antes e depois, ou o pouco espaço que eu preencho e vejo, mergulhado na infinita imensidade que ignoro e que não me conhece, tenho medo e espanto-me de estar aqui em vez de estar algures. Porquê agora em vez de antes? Quem me pôs aqui? Por ordem de quem e em que direção me foi este lugar e tempo atribuído? (PASCAL, 1952, apud LE BON, 2001).

O sentido da vida segundo Frankl (2005) difere de pessoa para pessoa, no contexto em que se encontra. Somente o sentido específico da vida de uma pessoa, em dado momento, é importante para dar significado à existência - é preciso haver um porquê viver.

A proposta reflexiva deste texto advém de uma pesquisa teórica de base 
bibliográfica oriunda dos estudos da Logoterapia, Filosofia e Teologia para sustentar o tema.

\section{Reflexões sobre o conceito de fé no âmbito da psicologia, da teologia e da filosofia}

No âmbito da Psicologia, o tema fé relaciona-se aos estudos sobre crenças. Crenças e opiniões influenciam o modo de agir de pessoas e, consequentemente, geram mudanças individuais, coletivas e tendem a produzir influências nos contextos socioculturais. Conhecer a origem das crenças, os mecanismos de sua formação, como se organizam os sistemas de crenças e como podem se modificar, tem sido objeto de interesse, também, da cognição social, campo de estudos que investiga os processos e conteúdos mentais, quando as pessoas se encontram em interação social. Conforme sinaliza Le Bon (2001), muitos creem que a crença é uma experiência racional e voluntária.

Pascal (apud LE BON, 2001, p. 107) diz que a fé é ato do coração, do mesmo modo que as crenças são resultado do agrado. Isso significa dizer que o homem crê naquilo que lhe agrada. Para Le Bon (2001) a crença não pode ser estudada pelas vias da lógica racional. As crenças e as opiniões são geralmente adotadas, isto é, assumidas por quem as propaga ainda que não haja um argumento lógico para sustentá-las.

Krüger (2019) propõe que as crenças individuais e ou coletivas compõem a estrutura do comportamento, dos preconceitos, dos valores e estereótipos. São elas que avaliam as experiências e atribuem-lhe valor e afetividade, orientando a ação.

As leis que regem as crenças e as opiniões apresentam aspectos distintos das que regem o conhecimento. Uma crença é, segundo Le Bon (2001), um ato de fé originariamente inconsciente e intuitivo, que obriga o homem a admitir uma idéia, uma opinião, uma explicação, uma doutrina. A crença só se torna conhecimento quando é verificada por meio da observação e da experiência, ou seja, por um método científico. Então, pela razão, cessa-se a crença e esta se transforma em conhecimento.

Diferentes áreas de estudos têm dedicado especial atenção às crenças. Entre os teóricos da Psicologia, Krüger (1986, p. 32) entende que "crenças são proposições que, na sua formulação mais geral, afirmam ou negam uma relação entre dois objetos concretos ou abstratos". Para o autor o estudo de crenças admite considerar o nível de consciência da pessoa que crê como um dos fatores que possibilita distinguir crenças mais nítidas de crenças menos nítidas. As mais nítidas influenciam a tomada de decisão e a avaliação de condutas, as 
últimas correspondem à base de respostas habituais.

Outro aspecto a considerar é o objeto das crenças que pode ser elemento real ou abstrato, cognitiva ou metacognitivamente apreendido. Crenças podem ser assimiladas de modo afirmativo ou negativo, e analisadas com relação ao tempo em que ocorrem. As ideologias, por exemplo, são crenças que têm seu início no passado e permanecem até o presente. Algumas crenças apresentam-se como enunciados descritivos, ligados à realidade; ou prescritivos, de caráter normativo e podem ser estudadas, também, com relação ao grau de consenso, isto é, extensão social de aceitação da crença que é a base da formação de crenças compartilhadas. O grau de consenso está diretamente relacionado ao nível de aceitação da crença, isto é, quanto mais houver consenso de pessoas em relação a crença, maior será o seu nível de aceitação (ROKEACH, 1981).

Outro aspecto a considerar em relação às crenças, segundo o autor, é a compatibilidade ou congruência, isto é, quanto maior o nível de congruência maior a probabilidade de articulação e formação de crenças. Assim sendo, é possível compreender crenças como sendo proposições de caráter pessoal ou coletivo adquiridas ao longo da vida e que regem as ações humanas em várias dimensões da vida de uma pessoa.

As crenças são formadas a partir dos valores pessoais. Estes consistem em representações cognitivas associadas às emoções e crenças, que motivam o indivíduo em direção a ações socialmente aceitas. São observados ou demonstrados pelo comportamento observável da pessoa e funcionam como critérios de avaliação de ações, pessoas, eventos, entre outros (GÓES, 2006). Afetam diretamente o modo como as pessoas vivem, o que elas consideram importante, o que julgam certo ou errado etc. (MARMITT, 2001).

Rokeach (1981) define os valores como uma crença única que conduz a ações e julgamentos e envolve objetos e situações específicas. Estão relacionados aos modos e condutas do indivíduo e constituem variável explicadora de sentimentos, atitudes e comportamentos. Os valores pessoais são importantes, pois ajudam a entender o modo pelo qual os indivíduos se apresentam e se relacionam com os demais integrantes de seu grupo social. Os valores são padrões que servem como referência para as ações e avaliações do indivíduo e dos outros.

Procurando distinguir entre os meios objetivos para uma determinada realização e os estados finais de existência, Rokeach (1981) subdivide os valores em duas categorias: os valores instrumentais e os valores terminais. Os valores instrumentais funcionam como 
instrumentos para se obter metas a serem atingidas ao longo da vida, são os modos ou meios preferenciais de comportamento escolhidos pelo indivíduo para esse fim. Os valores instrumentais originam-se no âmbito cultural e guiam os princípios de vida.

Os valores terminais representam um objetivo fim a ser obtido por meio da aplicação dos valores instrumentais. São as metas finais desejáveis que o indivíduo busca obter durante sua vida. Sua origem está no âmbito pessoal, embora estejam, em geral, relacionados a objetivos sociais. Os valores instrumentais e terminais são sistemas que interagem entre si funcional e cognitivamente (ROKEACH, 1981).

Para Rokeach (1981), crenças são parte de um sistema cognitivo integrado e formado também por atitudes e valores determinantes do comportamento humano. Uma mudança em uma parte desse sistema altera o comportamento, porém, nem todas as atitudes são guiadas por crenças e valores, apenas os relacionados a elas. O autor explicita que as crenças estão organizadas em sistemas estruturados e suas propriedades podem ser descritas, mensuradas e possuem consequências comportamentais observáveis. Assim sendo, são inferências que a pessoa faz sobre estados e expectativas básicas, sendo afetadas por razões sociais e pessoais, conscientes ou inconscientes.

Amatuzzi (2001) destaca que para entender a fé, é necessário primeiro estudar a motivação, depois o valor ou a ligação com um objetivo supostamente ainda não presente. E, em seguida a cognição ou crença que são afirmações acerca da realidade, vividas pela pessoa, não importa se verdadeiras ou falsas.

Para o autor, a fé refere-se àquilo que efetivamente anima a vida de uma pessoa ou lhe dá um sentido, nasce no sistema de crenças e relaciona-se com o esperado, com a determinação da ação, uma opção que mobiliza todo o ser. Ressalta que a fé é uma estrutura de sentido e de valores construída para dar significação à existência dentro do real. As pessoas tendem a vivenciar a fé, e é ela que dá sabor a nossa existência. É a aposta de cada um, que o faz viver. Dizer que o ser humano precisa de significação é dizer que ele constrói uma fé. A definição de fé neste artigo não está necessariamente associada à religião, mas ao conceito de crenças em Psicologia.

Com base no exposto, é possível perceber que para a Psicologia, a crença é uma necessidade humana e dela nasce o sistema de crenças e valores individuais. A partir desse sistema é que o indivíduo constrói a fé naquilo ao qual ele atribui sentido.

Nessa direção, Fromm (1995, p. 144) destaca que, em Psicologia, a fé "é uma convicção enraizada na própria experiência que se tem de pensamento ou sentimento." Ela se distingue da crença por ser racional. A crença é uma espécie de submissão de uma pessoa 
a uma autoridade irracional, seria a aceitação de algo apenas porque a maioria o afirma. Assim, a fé corresponde à firmeza e à certeza que as convicções pessoais possuem e tornase, por assim dizer, um traço de caráter, de personalidade e é baseada na própria observação produtiva e no pensamento racional, apesar da opinião de outros.

A fé no âmbito da Teologia é primeiramente estudada com base nas escrituras, na sua incidência e sua significação para o povo que a pronunciava, inserido dentro de um contexto histórico-cultural.

Em Born (1987), a fé para o Antigo Testamento (A.T.) é a atitude característica do homem perante Deus e subentende um consentimento da razão em reconhecer Deus e o que Ele representa para o povo. É a base para a esperança. A fé é a prova da existência daquilo que não se vê. Tem como objeto a esperança naquilo que não se tem, mas que se espera ter. No judaísmo é acentuado o aspecto intelectual da fé, é com base na palavra que se tem conhecimento de Deus, em primeiro plano relaciona-se com obediência e confiança. (Cf. Hc 2,4, 1 Sm 15,22, Jó 4,6; 11,18, Sl 27,3; 56,4; 71,5).

Gomes (1989) sinaliza que a concepção cristã de fé compreende uma atitude habitual de ser capaz de aderir ao que não se pode demonstrar com evidências concretas, mas sim, razoáveis à luz da razão. Une de algum modo, as acepções de uso comum, como opinar, ou possuir uma forte convicção, imbuída da carga afetiva de confiança, semelhante à concepção da Psicologia em que o indivíduo atribui sentido ao objeto de sua fé. Sendo a fé um ato da vontade, logo racional. Enquanto para a Filosofia, fé é a adesão àquilo que está fora do demonstrável, a fé, na Teologia, é atestada em proposições que parecem razoáveis, porém, não resolúveis ou demonstráveis.

Ainda para Gomes (1989), além de professar uma crença, o homem crente apoia-se em Deus. Suas afirmações são consequências de sua atitude de confiar. A fé é uma opção, a mais pessoal, mais íntima, mais caracterizadora, mais decisiva. O processo cognitivo da fé (confiar) é estimulado e provocado pela participação da vontade, da liberdade e do amor. Para crer, o homem se empenha volitivamente, em condição análoga ao ato de quem se deixa enamorar e fascinar.

A esse ato da vontade Gomes (1989) ressalta a exigência de uma disposição moral de desejar o bem prometido e oferecido por Deus, por intermédio de sua palavra. Fé é, então, resultado da liberdade. O simples "desejo de crer constitui certa orientação para Ele, é um apelo para a caridade como para seu fruto conatural" (1989, p. 17).

Segundo Aquino (1990, p.26), só é possível conhecer a Deus, quando se crê naquilo que está acima de tudo o que pode ser explicado e demonstrado pela razão, dado que a 
substância divina eleva-se acima do conhecimento natural do homem, do contrário não poderia ser designado Deus. E justifica sua necessidade ressaltando que "não obstante a razão humana não poder compreender plenamente as verdades que estão acima de si, contudo, ela adquire grande perfeição se ao menos as admite pela fé”.

Ainda Aquino (1990), destaca que o que é natural não pode mudar se a natureza permanece. Isso significa que se é natural ao homem crer e confiar naquilo que ele não explica racionalmente, o objeto de fé não desaparece, uma vez que sua natureza não é modificada. Assim, os argumentos contrários à fé não podem ser demonstrados e nem modificam sua natureza. Assim, a opção por crer naquilo que não é possível compreender, explicar ou demonstrar é exercício característico da razão humana.

Em síntese, no âmbito dos estudos da Teologia sobre fé, entende-se que o que a ciência não explica é objeto da fé, e, portanto, estudo da Teologia.

Zilles (1991) em sua obra "Filosofia da Religião", adotada nesse artigo, como referência para analisar as contribuições de diferentes filósofos relativa à evolução do pensamento sobre a relação acerca da fé e razão e sobre a existência de Deus, descreve vários pensadores e suas respectivas contribuições filosóficas a respeito da religião, um deles foi Descartes, o primeiro filósofo a pensar sobre a questão da fé com método científico e na sua obra o Discurso do Método, provocou o pensamento ocidental à refletir criticamente sobre a questão da existência de Deus, a relação entre fé e razão, e entre Teologia, Filosofia e ciência. O método cartesiano transferiu o lugar da certeza de Deus para a razão humana e assim o homem passa a ser capaz de chegar à certeza de Deus pela razão. Com essa premissa o teocentrismo medieval foi substituído pelo antroprocentrismo.

Ao aplicar seu método, o filósofo propõe que partindo da intuição racional é possível concluir que Deus existe, assim, explica que o argumento ontológico de Descartes é resumido pela idéia inata de Deus e pelo ser pensante. Para ele, o homem não criou Deus, pois é finito; o mesmo ocorre com a natureza, também finita, logo se a idéia de Deus está no homem isso ocorre porque Deus é a causa, ou seja, Ele existe. A idéia inata é a marca de Deus impressa no homem, sua obra. O fato de o homem pensar é a segunda prova de Deus. Do mesmo modo, é a partir da certeza de si mesmo que Descartes tenta basear a fé como fundamento filosófico da religião cristã. A fé é ato da vontade e não do intelecto cognoscente.

Ainda para o autor (1991), Pascal através da valorização do método empírico, propôs a incerteza como pressuposto para se conhecer a realidade, pois para ele em tudo 
há dois lados para analisar e assim estrutura seu método na dialética, ou seja, em cada verdade deve haver seu contrário. Por isso, não caberia à razão decidir a existência de Deus, mas apostar na crença em uma das opções que se tem, sem hesitar. Seu maior legado corresponde à sua definição de coração: o núcleo, o centro da pessoa e é dele a famosa frase "o coração tem razões que a própria razão desconhece", deste modo valoriza o conhecimento intuitivo e a fé é, então, a base da razão, pois ocorre na profundidade do coração. Pensa-se na fé e crê-se no pensar, na razão.

A Filosofia de Kant parte de uma teoria do conhecimento. Conforme Kant (2017) afirma que a existência de Deus não se prova pela razão, contrariando Descartes. Chega-se à existência de Deus pelo conhecimento intuitivo, que Kant (2017) chama de razão prática e na qual está a consciência moral. Ele reconhece a transcendentalidade, isto é, mediação subjetiva no conhecimento humano, em oposição à forma objetiva e demonstrativa de conhecimento. Com isso Kant (2017) liberta o pensamento ocidental do objetivismo ao reconhecer que um objeto só é objeto para um sujeito. A fé é uma escolha livre, autônoma e intuitiva.

Ainda em sua obra “Filosofia da Religião”, Zilles (1991) chega ao auge no sistema filosófico de Hegel, que nasceu numa Alemanha profundamente religiosa e foi educado no Cristianismo protestante, isto é, sob a ênfase no aspecto racional e moral da religião. Sua proposta de jovem era reformar a religião tornando-a tão racional quanto intuitiva. À Filosofia caberia pensar sobre Deus, e à religião servir de caminho para homens conhecerem a verdade. Assim, a fé é o conhecimento da verdade absoluta, daquilo que Deus é em si e para si e admite em seu método dialético, que Deus é, nesse contexto, um ser necessário: a realidade é finita e pode ser entendida pela razão, para o autor Deus é infinito e só pode se chegar a Ele pela fé.

Nos tempos modernos, permaneceu um embate entre a fé e a razão, com predominância da razão, a partir do advento da ciência. No entanto, o ser humano excede uma única dimensão a ele atribuída e questiona naturalmente o sentido da sua existência, que não se satisfaz, apenas, com a dimensão racional, e o leva a experimentar a fé como uma atitude que lhe corresponde e amplia a sua esperança para ultrapassar a finitude humana.

\section{O sentido da vida no contexto teórico da filosofia, da teologia e da logoterapia}


Muitas vezes, a vida se torna um amontoado de questionamentos, de dúvidas existenciais, de insatisfação, de busca por algo que faça sentido: o sentido da própria existência. O sentido da vida pode ser encontrado naquilo que se faz diariamente, naquilo que se vive e nas atitudes que se toma perante as circunstâncias da vida, normalmente as mais dolorosas. Este tópico tem como objetivo entender o sentido da vida no contexto teórico da Filosofia, da Teologia e da Logoterapia.

O papel fundamental da Filosofia é o da interrogação, na qual se procura conhecer o porquê último das coisas. O saber filosófico busca raiz dos problemas, onde tudo começa, e evita abordar as coisas superficialmente. Assim, a questão do sentido da vida é, por excelência, filosófica (NUNES, 2008).

O ser humano não é como os outros seres ou outros animais. Ele tem como elemento fundamental a necessidade de um sentido. O homem precisa de uma razão que justifique sua ação. Esses motivos podem ser utilitários, como razões para ter um trabalho, para se alimentar, para tomar esta ou aquela decisão, até motivos fundamentais, que explicam a própria existência e/ou permitem aceitar alguns aspectos da vida. Por essa razão, é possível afirmar que o Homem tem um pressentimento de que tudo tem um sentido, uma razão de ser, não se contentando em viver ao acaso, sem uma orientação superior (NUNES, 2008).

Os caminhos para encontrar um sentido para a vida são inúmeros. Algumas pessoas parecem encontrar esse tal sentido na existência de um ser superior, que é Deus; outros encontram-no na prática religiosa; ou há quem simplesmente encontre um sentido dentro de si mesmo (NUNES, 2008).

A humanidade sempre questionou filosoficamente o sentido de sua existência, o que pode ser visto nos seus diferentes sistemas de pensamento.

Um dos pensadores trazidos por Zilles (1991) acima para responder à questão sobre o sentido da vida é Leibniz, onde este defende que Deus confere sentido à existência. A única razão pela qual Homem e mundo existem é porque Deus decidiu criá-los e criou o melhor dos mundos possíveis. Deus funciona como razão suficiente do Mundo, ou seja, explica a sua existência. Nesse sentido, Aquino (1990) explica que Deus é um ser necessário e o homem um ser contingente.

Para justificar a existência do mal físico e moral, Leibniz (apud ZILLES, 1991) afirma que o mal físico existe para que se realize um bem maior, conduzindo a um estado superior. O mal moral é da responsabilidade humana e deve-se ao mau uso que o Homem faz da liberdade, da possibilidade de escolha entre várias alternativas. Deus preferiu salvaguardar a liberdade humana que considera como um bem maior relativamente ao mal moral. Aquino 
(1990) sustenta que, por ser contingente, a humanidade e o mundo estão em constante devir e não há mundo perfeito, há apenas o melhor mundo possível com os atributos que se tem no presente. Assim, o mal ou o que chamamos de mal é evolução, o homem ainda não desenvolveu, ou melhor, atualizou todo seu potencial. Este ainda está por vir a ser.

Contudo, a existência humana insere-se num contexto histórico, pertencente a uma determinada comunidade social. Qual o sentido da existência histórica do homem? Para responder a esta questão observam-se, segundo Zilles (1991) duas posições opostas: a pessimista, que encara a evolução histórica como a realização da decadência, e outra mais otimista, que acredita na ideia de progresso histórico.

Spengler (2013) manifesta a sua visão pessimista da História, anunciando o fim da cultura ocidental. A cultura ocidental teria entrado numa fase de decadência e, portanto, sena aniquilada. Por outro lado, a Filosofia socrático-platônica acreditava no progresso histórico e na regeneração da Humanidade. A regeneração seria possível pela via da Filosofia, purificadora, ou pela via. O Homem se tornaria virtuoso e alcançaria a verdade.

Camus (1957, apud ZILLES, 1991) ao responder sobre a questão da existência conclui que a condição humana é essencialmente absurda. Para ele há um divórcio entre a condição do ser humano e o mundo, isto é, há um choque entre uma ausência de sentido e um ser que tem como condição a procura de sentido. A necessidade de buscar um sentido para vida é uma necessidade humana. Este divórcio, segundo o autor, provoca angústia no ser humano o que pode explicar em parte a questão do suicídio. Se o homem não precisasse buscar um sentido, não teria problema o mundo ser sem sentido.

Cifuentes (2005) descreve que a relação estreita entre sentido de vida e a questão da fé, que não apenas aborda o ângulo religioso, mas algo que compromete a integralidade do homem, uma vez que o problema da existência de Deus está diretamente relacionado com a questão que mais profundamente compromete o homem, que é o sentido da própria vida. Somente a pessoa caracterizada com “ser humano” procura a razão de sua existência, o que o diferencia de todas as ouras criaturas. O autor traz a encíclica Fides et Ratio de João Paulo II para descrever com clareza o surgimento de questionamentos fundamentais, como por exemplo: Quem sou eu? Donde vim e para onde vou? O que é existirá depois dessa vida? Percebe-se que estas perguntas existem ao longo dos textos sagrados, pois revelam que têm a sua fonte comum na exigência de sentido, que desde sempre, urge no coração do homem.

Outro teólogo que contribui para as reflexões sobre sentido de vida e fé é Giussani (2008) que afirma que a fé se manifesta inicialmente a partir de um encontro que o homem faz com Deus em sua experiência cotidiana do humano. Este encontro se caracteriza por 
uma presença excepcional que gera a excepcionalidade, tal como ocorreu com João e André, ao encontrar Jesus. A experiência revela que se trata de um fato "não normal, é um encontro não normal; é um encontro-encontro, quer dizer tem uma característica de excepcionalidade, pela qual é levado em consideração” (GIUSSANI, 2008, p. 41). Ainda nesta experiência, o que se segue é o maravilhamento, que suscita a impressão absolutamente excepcional de algo sobre-humano e que fortalece e define o que dá sentido para viver. Por último, realizar sentido de vida na perspectiva da fé, segundo autor, decorre da pergunta, quem é este que me permitiu o encontro de modo tão excepcional que gerou, o maravilhamento para decidir o meu viver?

O termo logos é de origem grega e significa sentido, e é na busca do sentido da existência humana que a Logoterapia mantém seu foco. Os sentidos são mutáveis e para Frankl (2005), cada mudança corresponde a um renascimento maior que o anterior, um crescimento pessoal, pois mudar e crescer causam dor e conflito. Essas ações implicam renúncias e abertura ao desconhecido, ao novo, entretanto, o conflito é normal e sadio, do mesmo modo o sofrimento pode ser uma realização e não uma patologia, pois a frustração existencial é necessária para o amadurecimento humano. A busca por sentido pode causar tensão interior em vez de equilíbrio interior, e essa tensão é causada pelo movimento em direção ao novo, ao ponto em que se quer chegar, é um pré-requisito indispensável para a saúde mental, pois o fator mais importante para a sobrevivência ainda que nas piores condições, é saber que a vida tem um sentido. Para o autor, ter por que viver faz com que a pessoa suporte qualquer condição de sofrimento, ou privação, ou sacrifício.

Uma vez que a saúde mental de uma pessoa está no ponto de tensão, Frankl (2005) define a Logoterapia como um método terapêutico centrado no sentido que tira a atenção das formações e mecanismos retroalimentadores centrados no passado e dirige o foco da atenção para os sentidos futuros, aqueles que ainda serão realizados. Desse modo, a pessoa deveria ser desafiada a direcionar o sentido naquilo que há de potencial para ser realizado, como forma de despertar o seu desejo de sentido latente e inerente.

Para Frankl (2005), o ser humano precisa da busca e da luta por um objetivo que valha à pena, uma tarefa escolhida livremente, e neste caso, os terapeutas deveriam aproveitar da tensão própria do viver para reorientação na direção do sentido da vida. No mundo atual, parece ser frequente a existência de pessoas para quem falta sentido em suas vidas, que são carentes da consciência de um sentido pela qual valha à pena viver. Sentem-se perseguidos e tomados pela experiência de um vazio interior, isto é, de um vazio dentro de si. A esta situação o autor denominou de vazio existencial.

No início da História da humanidade, segundo Frankl (2005), o ser-humano era 
governado basicamente por instintos que com a evolução da espécie humana foram diminuindo sua influência como fator básico para o controle do comportamento. Disso resultou a necessidade de que fosse orientado a agir por fatores externos a si, como crenças, valores e tradição. Atualmente com a redução das tradições, fator que servia de apoio e orientação para o comportamento, o homem tem dificuldade em saber o que deseja fazer. Sem os instintos guias e as tradições, o homem passou a desejar fazer "o que os outros fazem (conformismo), ou a fazer o que as outras pessoas querem que ele faça (totalitarismo)" (p.97). O vazio existencial pode resultar desse processo, de acordo com Frankl (2005), e se manifesta num estado de tédio. Esse sentimento surge quando a pessoa não sabe o que fazer com esse tempo livre adicional. Para a Logoterapia, a busca de sentido da vida é a principal motivação no ser humano.

O sentido da vida difere de pessoa para pessoa e em função das circunstâncias, daí a importância que a Logoterapia atribui ao sentido da vida de uma pessoa em dado momento. O ideal é que cada pessoa adquira a consciência de sua própria vocação ou missão específica na vida. Para tal, é necessário que cada um encontre na vida uma tarefa concreta ou uma razão para viver que lhe permita experimentar realização. Nesse empreendimento, a pessoa não pode ser substituída, nem pode sua vida ser repetida. Assim, nas palavras de Frankl (2005, p. 98) "a tarefa de cada um é tão singular como a sua oportunidade específica de levá-la a cabo".

Outro aspecto que contribui para a busca de sentido da vida, conforme explica Frankl (2005), é a existência de problemas que precisam ser resolvidos. Cada situação na vida corresponde a um desafio e a um problema para resolver. A pessoa deveria reconhecer que está sendo indagada pela vida. A resposta dada à vida corresponde à solução encontrada e cada um só pode responder por sua própria vida e à vida. A pessoa somente pode responder sendo responsável. A Logoterapia vê na responsabilidade a essência propriamente dita da existência humana. Por essa razão, busca estimular no paciente a plena consciência de sua responsabilidade em realizar o sentido potencial de sua vida.

Para Frankl (2005), todo homem busca constantemente um significado para a sua vida. Essa é a motivação primária da existência humana. Na sociedade atual, satisfazer o desejo de sentido é cada vez mais difícil. O sentido da vida pode ser encontrado nas respostas que as pessoas dão aos fatos que experimentam ao longo de sua existência. Esse sentido é exclusivo e específico, pois é particular. É na exclusividade e na particularidade que o sentido assume importância e preenche a necessidade, satisfazendo a própria vontade de sentido. Embora muitos teóricos relacionem os sentidos de vida a mecanismos de defesa ou formações reativas e sublimações, o autor defende que o sentido da vida está 
relacionado aos ideais superiores e valores éticos.

Frankl (2005) salienta que o verdadeiro sentido da vida precisa ser descoberto no mundo. O ser humano sempre se direciona para algo ou alguém fora de si. Essa característica constitutiva é denominada pelo autor de a autotranscedência da existência humana. Quanto mais a pessoa volta-se para servir uma causa ou amar a outra pessoa, mais humana se torna e mais se realiza. A autorrealização só é possível como consequência da autotranscedência. A autotranscedência também dá sentido ao trabalho, à realização pela profissão ou pela atividade laboral, seja ela qual for, assim como a qualquer atividade a que o ser humano venha a se dedicar.

A ausência de sentido no trabalho pode estar relacionada ao tédio, à necessidade de atribuir-lhe um significado que dê sentido à vida, que possa ser experimentado como missão, além da própria prática profissional. Neste contexto de reflexão, espera-se que possa estar relacionado à atividade criadora quando impulsiona o homem ao agir, ao seu papel e valor dentro da comunidade. O valor que a pessoa conquista no grupo está relacionado à sua contribuição para a comunidade e é essa contribuição que representa o sentido do trabalho, porém, a missão de servir ao outro exige amor. O único caminho para alcançar o ser humano no íntimo da personalidade é o amor, como destaca Frankl (2005) ao dizer que só se tem consciência plena da essência última de outro ser humano amandoo. É o amor que faz com que a pessoa seja capaz de ver as características essenciais do amado e as suas potencialidades, é também o amor que capacita o ser amado a realizar suas potencialidades. O sentido do amor está para além do caminho da realização, dos valores criadores e refere-se ao alcance do caráter de algo único. É a busca por esse algo único que dá sentido ao amor.

Nas adversidades também é possível encontrar sentido na vida. As situações sem esperança estimulam o ser humano a transformar a tragédia pessoal em vitória. Frankl (2005) explica que o sofrimento ao encontrar um sentido perde o sentido de sofrimento e adquire outro, tal como o sentido de um sacrifício. A capacidade em dar sentido ao sofrimento corresponde a um dos princípios fundamentais da Logoterapia: a principal preocupação da pessoa consiste em ver um sentido em sua vida. Por essa razão, o ser humano está disposto a sofrer, se o seu sofrimento tiver um sentido. Merece ênfase a capacidade humana de encontrar sentido para vida a despeito do sofrimento. "O sentido da vida é um sentido incondicional. por incluir até o sentido potencial do sofrimento inevitável" (p. 102).

Frankl (2003) ao falar sobre o sentido do sofrimento distingue três aspectos dessa 
dimensão: valores criadores corresponde à ação, ao fazer no mundo valores vivenciais - à acolhida do "eu" no mundo e valores de atitudes à resposta dada ao que se deve aceitar por ser inevitável. isto é, não se pode reagir contra.

Assim, a resposta dada ao acontecimento pode ser positiva, de esperança, uma atitude de fé diante do fato, ou negativa, de desesperança, isto é, de desespero eliminando da pessoa a possibilidade de responder ao sofrimento numa atitude racional e positiva.

Outro aspecto que envolve o sentido do sofrimento está relacionado à necessidade. Frankl (2003) destaca que a vida humana é um contínuo ir e vir entre necessidade e tédio. O tedio relaciona-se à ociosidade. O tédio lembra o sujeito da missão que ele precisa cumprir e o move à ação. De mesmo modo funciona a necessidade que age como um lembrete que move o agir para livrar a pessoa da apatia. Assim o sofrimento induz ao agir.

A Logoterapia questiona o fim último do sofrimento humano. Por isso, se propõe a estimular o paciente a suportar a incapacidade de compreender racionalmente o fato de que a vida tem um sentido incondicional. "O logos é mais profundo que a lógica" (FRANKL. 2005, p. 105). No intuito de estabelecer uma correlação, a Logoterapia reconhece que o paciente ancorado sobre a fé religiosa se vale dos efeitos terapêuticos das suas convicções espirituais.

Nesse sentido a Logoterapia destaca que a preocupação ou o desespero da pessoa sobre se a vida vale a pena ser vivida é uma angústia existencial. A angústia provocada pelas tensões de cada situação na vida representa um desafio para a pessoa e lhe apresenta um problema para resolver. E a fé em alcançar a solução ou uma situação diferente da atual que auxilia a pessoa a galgar sentidos para seu sofrimento e a para sua existência.

\section{Fé e sentido da vida}

Conforme abordado anteriormente, tem sentido aquilo que significa algo de modo simbólico para uma determinada pessoa ou grupo social. Segundo Savater (2001), é a ânima que determina o sentido de uma coisa. Se não há vida, não há intenção e, portanto, perde o sentido. Para encontrar o sentido da vida é preciso transcender a própria vida.

O pensamento teológico acerca do sentido da vida preconiza que a finalidade da existência humana é a felicidade alcançada pelo "religare" ao criador, ou seja, Deus é a finalidade última do homem. De acordo com Boff (1998), a religião só persistiu e resistiu ao movimento antropológico do humanismo, do renascimento e, posteriormente, ao iluminismo e ao existencialismo moderno, porque ao longo dos séculos ela ressignificou 
a identidade do homem, a sua vida e a sua morte. Assim, o pensamento teológico acima apresentado favorece a relação com o conceito de sentido de vida, pois em ambos se encontra a ideia da intenção, do significado e o ser humano atribui às suas crenças, neste caso, as crenças em Deus ou na existência de um ser superior favorecem a dar sentido a vida humana.

De acordo com Nunes (2008) o próprio Deus comunicou ao ser-humano a finalidade de sua existência por intermédio da Bíblia e de outras formas de revelação. Deus dá sentido à existência humana, de modo que homem perceba que o sentido de sua vida, não se realiza na vida terrena, mas na dimensão espiritual. Ele, de modo pleno, só pode ser alcançado numa existência depois desta vida, na qual a alma imortal permanecerá eternamente no reino de Deus. O sentido da vida está ao alcance de todos os homens, uma vez que Deus os fez à sua imagem e semelhança. Porém, só alcançará a realização de sentido, o homem que viver neste mundo uma vida direcionada aos valores éticos, na qual a prática do bem e a fé são condições essenciais. Isso significa que o objetivo de alcançar a realização de sentido pleno na vida em Deus, por Deus e com Deus é que dá significado e valor à vida do ser humano neste mundo.

Kant (2017) destacava que se a vida não fosse eterna não faria sentido. Para o referido autor, somente Deus e a imortalidade podem dar sentido à existência humana. Atualmente, Craig (2018) é o filosofo que defende essa idéia. Ele ressalta que a vida humana e a totalidade do universo só têm sentido, valor ou propósito se Deus existir e se a alma humana for imortal. Do contrário, nada do que fizermos tem sentido, valor ou propósito e tanto o universo como a vida humana são absurdos.

Ser religioso, segundo Boff (1973), significa perguntar insistentemente e amorosamente pelo sentido da vida e estar aberto para respostas, sejam elas quais forem, ou mesmo quando elas nos chocam e abalam profundamente.

Assim, com base nesse argumento, é a fé em Deus e na imortalidade da alma que dão sentido à vida humana.

A questão do sentido da vida é essencialmente filosófica. O ser humano tem por elemento constitutivo a necessidade de atribuir à própria existência um sentido. Assim a fé, conforme já foi dito, é o que impulsiona a ação. Para Savater (2001), julgar se a vida merece ou não ser vivida, é objeto de reflexão filosófica. Esse interesse em atribuir sentido à vida é intelectual e natural. A fé também é movimento determinado pela inteligência. É ato da vontade. Atribuir sentido à vida é crer em algo sobre o qual o serhumano é capaz de dar significado. Nesse sentido, o autor explica que o sentido do mundo deve estar fora do mundo. O maior de todos os sentidos é a intencionalidade vital 
ou a intenção humana.

La Taille (2006) ao refletir sobre a ética destaca que os valores ou o sistema de valores de um indivíduo são consequência do valor que ele atribui à sua vida, isto é, do sentido que ela tem para ele. Isso significa dizer que, atendendo à primeira necessidade de dar sentido (valor a si) à vida, o passo seguinte é inserir ao valor de si próprio o bem que pode ser feito a si e ao outro.

Amatuzzi (2001) demonstra que a fé corresponde, então, ao elo que conecta a ação ao objetivo a ser alcançado. Esse objetivo encontra-se numa estrutura de valores construídos pela fé e que conferem significado ao agir, à existência humana. $\mathrm{O}$ autor ressalta, ainda que essa fé não precisa ser religiosa, mas poderá tomar-se religiosa conforme sua intensidade remetendo a ação a um sentido universal que dá sentido à vida.

A Logoterapia, segundo Frankl (2003), dedica-se a estimular a que a pessoa tornese consciente do sentido de própria existência. O autor explica que o ser-humano não pode compreender além do mundo que o circunda e para vislumbrá-lo teria que ir além da fé. Isso significa afirmar que assim como um animal não pode entender, para além de seu mundo circundante, assim também o homem não poderia aprender o supra mundo, isto é, o mundo que o ultrapassa. O único meio de alcançar tal mundo, portanto, seria ir mais longe, vivenciando-o na fé.

Conforme foi dito no primeiro tópico, é objeto de fé o que transcende à razão. É escolha de a inteligência acreditar naquilo que a ciência não explica ou comprova empiricamente. Assim, para a Logoterapia de Frankl (2003, p. 64) "a entrada na dimensão supra-humana, efetiva na fé, funda-se no amor".

O autor destaca que a fé que transcende à razão adquire importância psicoterápica e psico-higiênica. Ele considera a fé um agente criador, pois dela brota a força interior capaz de tornar o homem forte o suficiente para modificar a realidade, ressignificando-a e dando sentido a sua vida. Logo, para o autor (p.64), a história interior da vida de um homem nunca acontece 'em vão' em todo o seu drama pessoal e, inclusivamente, na sua tragédia.

A Logoterapia não se pronuncia objetivamente sobre fé, mas permite admiti-la no contexto de transcendência. Para Frankl (2011, p. 67) "a existência não é só intencional, como também transcendente. A autotranscedência constitui a essência da existência. Ser humano é ser direcionado a algo que não si mesmo” (Frankl, 2016, p. 92), e com isso o autor entende que a fé num suprassentido, tem uma grande importância psicoterápica e psico-higiênica, pois ela brota de uma força interior e torna o homem mais humano e 
forte.

\section{Considerações finais}

O sentido da vida constitui um questionamento filosófico acerca do propósito e significado da existência humana. É encontrado pelo indivíduo conforme o seu sistema de crenças e valores.

O sistema de crenças e valores de urna pessoa é construído ao longo de sua vivência e com base na sua experiência individual e coletiva, na integração com o meio sociocultural e no modo como estabelece e realiza suas relações interpessoais.

Existem várias respostas possíveis para o tema, uma vez que o sentido da vida é individual. Cada um encontra sentido para sua existência de acordo com a própria consciência que apreende os valores subjacentes na realidade vivida. Porém, com frequência, as respostas estão vinculadas às convicções religiosas ou filosóficas. Entretanto, vale ressaltar que o sentido da vida também pode variar ao longo da vida, conforme a maturidade, ou as circunstâncias do momento presente ou das experiências vividas. No entanto, de urna forma mais ampla, não existe consenso sobre tal, pois depende de cada pessoa no contexto de sua existência.

Para o pensamento religioso o sentido da vida está estreitamente associado a Deus, ao sagrado. Para o pensamento laico, é o homem quem fixa o sentido da vida, por via das suas opções e valores. O homem é o único animal para quem a existência é um problema que ele tem que resolver. Assim, a busca pelo sentido da vida tornou-se um problema. Alguns autores sublinham o caráter instintivo associado ao sentido que atribuímos, neste caso o sentido da vida está dentro de nós, é ontológico e ultrapassa as variáveis culturais e sociais. Para a Logoterapia, o sentido da vida é alcançado pela realização de valores e também por meio da fé.

Desta forma, é possível supor que o sentido da vida tem uma estreita relação com a fé, uma vez que os dois conceitos se configuram como crenças para viver. Acreditar na existência de um Ser Superior, Criador, essência do Bem e da Verdade, corresponde ao homem transcendente, que não se limita ao psicofísico como aquilo que o representa. A Logoterapia fala da dimensão noética do homem, que constitui o lócus do sentido, que reúne atributos humanos, próprios de sua dimensão ontológica e nela concentra-se a consciência, a liberdade, a responsabilidade, os valores, a criatividade, a espiritualidade, que impulsionam o homem para admitir a transcendência, como possibilidade para 
enfrentar a finitude. Neste caso, a fé é o elo que viabiliza a dimensão espiritual do homem, que dá sentido ao seu viver, numa certeza de que não está sozinho nessa busca.

\section{REFERÊNCIAS}

AMATUZZI, M. M. Por uma Psicologia humana. Campinas: Alínea, 2001.

AQUINO, Santo Tomás de. Suma contra os gentios. VI. Porto Alegre: Universidade de Caxias do Sul, 1990.

BÍBLIA. Português. A Bíblia de Jerusalém. Nova edição rev. e ampl. São Paulo: Paulus, 1985. BOFF, Leonardo. O despertar da águia: o dia-bólico e o sim-bólico na construção da realidade. Petrópolis: Vozes, 1998.

Vozes, 1973.

O destino do homem e do mundo: ensaio sobre a condição humana. Petrópolis:

BORN, A. Van Den. (org.) Dicionário enciclopédico da Bíblia. 4 ed. Petrópolis: Vozes, 1987.

CIFUENTES, Rafael Llano. Deus e o Sentido da Vida. São Paulo: Ed. Marques Saraiva, 2001. CRAIG, William Lane. Apologética para questões difíceis da vida. Sociedade Religiosa Edições Vida Nova, 2018.

DANTAS, M. A.; TOBLER, V. L. O sofrimento psicológico é a pedra angular sobre a qual repousa a cultura de consumo. Congresso da ABRAPSO. Anais... Brasil, 2003. Disponível em: < http://www.psicologia.com.pt/artigos/ver_artigo.php?codigo=aOl $75>$. Acesso em: 14 out. 2020.

DE AQUINO, Thiago Antônio Avellar et al. Estilos de fé e sentido da vida. Psicologia Argumento, v. 31, n. 75, 2013.

FRANKL, Viktor E. A vontade de sentido: Fundamentos e aplicações da logoterapia. Trad. Ivo Studart Pereira. São Paulo: Paulus, 2011.

. Em busca de sentido: um psicólogo num campo de concentração. Trad. Walter O. Schlupp e Carlos C. Aveline; revisão técnica de Helga H. Reinhold. 21.ed. São Leopoldo: Editora Sinodal; Petrópolis: Vozes, 2005.

Psicoterapia e sentido da vida: Fundamentos da Logoterapia e análise existencial. Trad. Alípio M. de Castro. 6. ed. São Paulo: Quadrante, 2016.

FROMM, Erich. A arte de amar. Belo Horizonte: Ed. Itatiaia Limitada, 1995.

GIUSSANI, L. É possível viver assim? Uma diferente abordagem da existência cristã. $2^{\mathrm{a}}$ Edição - São Paulo: Companhia Ilimitada, 2008

GÓES, A. M. M. Valores relativos ao trabalho como antecedentes do comprometimento organizacional. Dissertação Mestrado. Programa de Pós-Graduação em Psicologia, 
Universidade Católica de Brasília, Brasília: UCB, 2006.

GOMES, D. Cirilo Folch O.S. B. Riquezas da Mensagem Cristã. 2.ed. Rio de Janeiro: Lúmen Christi, 1989.

KANT, Immanuel. Crítica da razão prática. Editora Vozes Limitada, 2017.

KRUGER, H (Org). Cognição Social: teoria, pesquisa e aplicações. Curitiba: CRV, 2018. . Introdução a Psicologia Social. São Paulo: EPU, 1986

. Psicologia das crenças. Curitiba: CRV, 2019

LA TAILLE, Yves. Moral e ética: dimensões intelectuais e afetivas. Porto Alegre: Artemed, 2006.

LADRIERE, Jean. Ciência, Filosofia e Fé. ln: A Articulação do Sentido. São Paulo: EPU, 1977, p. 157-158.

LE BON, Gustave. As opiniões e as crenças. Disponível em: file:///C/site/LivrosGrátis/asopinioes.htm ( 1 of 141).Postagem [05/04/2001 16:56:46] Acesso: 13/04/2011.

MARMITT, C. Semelhanças e diferenças de valores pessoais entre consumidores de eletrodomésticos nos municípios de Lajeado e Estrela-RS. Dissertação de Mestrado. Programa de Pós-Graduação em Administração, Universidade Federal do Rio Grande do Sul. Porto Alegre: UFRGS, 2001.

NUNES, Álvaro. A religião e o sentido da existência: a experiência da finitude e a abertura à transcendência. Artigo. 2008. Disponível em: <http://www.filedu.com/anunesareligiaoeosentidodaexistencia.html> Acesso: $12 / 06 / 2020$.

PONTES, SANTOS, ZANATTA CLAVERY GURANIDO DUARTE (orgs) . O Legado de Viktor Frankl: caminhos para uma vida com sentido. Ribeirão Preto: IECVF, 2020.

ROKEACH, M. Crenças, atitudes e valores: Uma teoria de organização e mudança. Rio de Janeiro: Interciência, 1981.

SAVATER, Fernando. Perguntas da vida: O ser humano e o sentido da existência. ln: O canto da filosofia. 2001, p. 267-275. Disponível em: <www.edusurfa.pt_mostra_pdf> Acesso: 22/05/2011.

SPENGLER, Oswald. A decadência do Ocidente. Rio de Janeiro: Forense Universitária (2013) ZILLES, Urbano. Filosofia da Religião. São Paulo: Edições Paulinas, 1991. 